\title{
DEGUSTAR PSICODRAMA ON-LINE COM PORTADORES DE OBESIDADE. VOCÊ ACEITA?
}

\author{
Ana Cristina Benevides Pinto ${ }^{1,2, *}$ (iD
}

\section{RESUMO}

A autora partilha experiências de atendimento psicodramático on-line com pacientes obesos, como em uma degustação, que inspira a criação de recursos e reflexões sobre a prática psicoterápica em tempos de pandemia do Covid-19, bem como em novos tempos, demonstrando a viabilidade do referencial psicodramático nesta modalidade.

PALAVRAS-CHAVE: Psicodrama on-line; Obesidade; realidade suplementar; Lógicas afetivas de conduta; Representante relacional simbólico.

\section{TASTING ONLINE PSYCHODRAMA WITH OBESITY SUFFERERS. DO YOU ACCEPT?}

\begin{abstract}
The author shares experiences of psychodramatic care online with obese patients, as a tasting, which inspires the creation of resources and reflections on psychotherapeutic practice in times of the Covid-19 pandemic, as well as in new times, demonstrating the viability of the psychodramatic reference in this modality.
\end{abstract}

KEYWORDS: Online psychodrama; Obesity; Supplementary reality; Affective logic of conduct; Symbolic relational representative.

\section{DEGUSTAR PSICODRAMA EN LÍNEA CON PACIENTES OBESOS. ¿ACEPTAS?}

\section{RESUMEN}

A través del relato de sessiones el autor comparte sus experiencias de atención psicodramática en línea con pacientes obesos, por lo cual inspira la creación de recursos y reflexiones sobre la práctica psicoterapéutica en tiempos de la pandemia Covid-19, así como en los nuevos tempos, demostrando la viabilidad del marco psicodramático en esta modalidad.

PALABRAS-CLAVE: Psicodrama en línea; Obesidade; Realidad suplementaria; Lógica afectiva de conducta; Representante relacional simbólico.

1.Centro de Tratamento e Integração do Ser - Fortaleza (CE), Brasil. 


\section{APERITIVO AMARGO: SEÇÃO INTRODUTÓRIA}

O início da pandemia do coronavírus foi denso e muito indigesto. As notícias, os fatos e as percepções traziam incertezas, angústias e indignações de difíceis ingesta e digestão. O isolamento social surge com o sabor amargo de óleo de rícino, apesar de ser uma possibilidade de alívio para auxiliar a absorção do que estava sendo posto à nossa frente, operacionalizado por súbitas mudanças, comboiando a segurança, o medo e os impactos em todas as searas da vida.

Mesmo que ainda não consigamos dimensionar, muitos aspectos da nossa vida mudaram e estão mudando com a pandemia da Covid-19. Nesta comunicação, destaco a relação com a comida e o aumento significativo da obesidade, em um curto espaço de tempo. Tal relação está entremeada por inúmeros fatores, como o aumento da ansiedade, a oferta e a entrega em domicílio de alimentos calóricos e pouco nutritivos, a convivência familiar, quase que ininterrupta, a sobrecarga de trabalho, ociosidade ou desemprego, a demanda dos afazeres domésticos, a criação dos filhos, a redução do convívio com familiares idosos ou extensivos, com amigos, com grupos de apoio, e a ausência de exercício físico regular, na intensidade necessária para quem está na luta contra o persistente excesso de gordura.

Ademais, a pandemia trouxe um agravo identitário de pertencer ao grupo de risco, o que, além de invocar o medo da morte, da doença, dispara raiva de si mesmo e arrependimento por ter chegado ao estado obeso, seja qual grau for.

Compartilho a descrição de dois atendimentos psicoterápicos, com referencial psicodramático, realizados na modalidade on-line, com pacientes obesos. Ressalto a preservação do sigilo profissional e dos aspectos éticos para a exposição dessas informações.

\section{O PROCESSO DIGESTÓRIO: SEÇÃO DE DESENVOLVIMENTO}

Nesse cenário pandêmico, o papel de psicoterapeuta on-line constrói-se no estado permanente de compartilhamento, não só na cena psicodramática, como também no contexto social, adequando a construção do papel complementar de cliente/ paciente on-line. Aquecemo-nos de várias formas, desde a escolha do local físico de atendimento: moradias do cliente e/ ou do terapeuta, até as condições favoráveis à privacidade e ao sigilo, às plataformas, à qualidade expressa na velocidade da conexão digital e à inserção desta prática.

Nesse papel, recém-nascido, a confiança na criatividade é o grande combustível, faz-nos fluir na realidade suplementar (Perazzo, 2010), creditando ao imaginário compartilhado o surgimento dos recursos necessários para desvendarmos os caminhos de busca da verdade psicodramática e poética.

Não ter outra opção foi motivador! De repente, eu estava com pacientes antigos em cenários novos, emboscados por uma crise mundial, que nos assolava ao mesmo tempo. Acho que isso é importante para corrigir qualquer idealização que os pacientes possam fazer de nós e para desenvolvermos nossa consciência comum de vulnerabilidade — tatearmos juntos na escuridão de um sofrimento tão vividamente coletivo.

O primeiro atendimento é do L, adulto, com obesidade grau II (IMC entre 35 e 39,9), após dois anos de cirurgia bariátrica e com algumas alterações nas taxas sanguíneas, comprometedoras da sua saúde orgânica. Está em acompanhamento psicoterápico comigo desde fevereiro de 2020. Iniciamos o atendimento on-line no mês seguinte, sempre no seu escritório, em casa, onde sente privacidade e resguardo para trabalharmos.

Em uma sessão no início de maio, ele entrou com sinais de estar aquecido, verbalizando a queixa de que não conseguia abotoar as calças, pois o ganho de peso foi enorme. Estava irritado. Pedi que ele fizesse com as mãos os gestos de tentar colocar o botão no caseado e, à medida que ele fazia o gesto, eu incentivava que ele desse voz ao botão, enquanto eu dialogava com esse personagem.

Botão: "Não adianta, não tem mais jeito de eu entrar aí! Se forçar mais, eu vou me despregar e vai ser pior".

Terapeuta (T): “O que seria pior?”.

Botão: “Eu não segurar mais a calça e o L sair por aí com o buchão de fora. Foi comer demais, agora aguenta, p****”. 
Pedi que congelasse a cena, respirasse e buscasse dentro dele a voz que diz que ele tem que aguentar. De imediato, veio uma cena com o pai, compulsivo, alcoolista e moribundo, dizendo que ele teria que ser forte para aguentar o que estava por vir.

T: “O que está por vir?”.

L: "A morte dele e depois a depressão da minha mãe".

T: "Quantos anos o L tem nesta cena?”.

L: "14 anos".

T: “Olha para ele, chega perto e sente como está o coração dele”.

L: "Acelerado e a barriga congelada por dentro".

T: "O que congela a barriga e acelera o coração?".

L: "As palavras do pai dele.".

T: "Ocupa o lugar do pai e fala estas palavras congeladoras para o L".

L, no papel do pai: "L, chegou a hora de você ser mais forte, pois daqui a pouco, será você o homem da casa. Terei que partir".

T, no papel de L com 14 anos: "Pai, suas palavras estão me dando tanto medo, que sinto um frio horrível na minha barriga. Meu coração vai já sair pela boca”.

L, no papel do pai: "Engole o coração! Esta é a hora de ser forte! Você tem muitas responsabilidades pela frente e eu só tenho você para deixar com elas!"

Peço ao L para ocupar o lugar dele com 14 anos e responder ao pai.

L com 14 anos, com a voz embargada: "Eu estou tentando ser forte, mas também estou com medo. Não quero perder você!".

T, no papel de pai: "Não temos escolha, nem eu nem você".

L, com 14 anos, fica paralisado e eu peço um solilóquio: "Eu estou sozinho, tenho que me virar comigo mesmo. Não tenho com quem contar!".

T: "Volta a ser o L de hoje e olha para este rapaz de 14 anos. O que ele aprendeu neste momento da vida, que está presente até hoje?".

L: "Que ele tem que ser forte sempre e engolir o medo".

T: "Olha para ele, nesse difícil momento da vida dele, como ele está?".

L: "Engolindo o medo...”.

T: "Assim como você embargou o choro há pouco? Experimenta chegar perto dele para ver o que você sente. A tua mão direita é você hoje e a esquerda é ele".

Neste momento, L. coloca as suas mãos paralelas uma a outra, após eu fazer o gesto com minhas mãos, fui conduzindo: aproxime-se, faça o que você precisar com esse garoto e veja no que ele precisa de você.

L: "O pai faz tanta falta para mim até hoje! Eu sei que dói demais o que você está sentindo".

Em seguida, ele esfrega as mãos e começa a dizer chorando: "você ficou tão perdido, mas quando viu a mãe no quarto trancada sem querer viver mais, você entendeu o que o pai dizia sobre ser forte”.

T: "Agora vocês podem chorar essa dor, essa morte e se tornarem fortes, sem negar o que estão sentindo. É preciso coragem para olhar para o sofrimento. Vá acariciando o L. de14 anos e faz o que vocês precisam".

Ele comprimiu as mãos e liberou o choro copiosamente por vários minutos. Não desatou as mãos até parar de chorar e dizer: “juntos somos fortes!".

Em seguida, pedi que ele olhasse para as mãos dele como se fosse uma escultura e desse um título. Ele parou e disse: “juntos somos fortes!”.

Voltei para a cena do botão e perguntei o que $\mathrm{L}$ poderia dizer ao botão agora.

L: "Não vou forçar a barra agora. Vou fazer os exercícios on-line, parar de pedir Ifood e emagrecer. Depois voltamos a conversar, pois preciso de você para segurar a barra!" Começou a rir.

No compartilhamento, perguntei como ele estava e ele referiu alívio, explicando que foi um jeito diferente de olhar para a morte do pai e para a depressão da mãe, sem tanta cobrança interna. 
Nas sessões consequentes, ele trouxe temas ligados à relação com a comida, destacando que recorria a ela com a ânsia de ficar forte para enfrentar as adversidades. Mas agora, queria se sentir leve e bem nutrido. Estamos construindo este estado físico e emocional. Ele continua em psicoterapia comigo.

O segundo atendimento é de I, que está em acompanhamento psicoterápico há cinco anos, adulto, com obesidade grau I (IMC entre 30 e 34,9). Perdeu quase $40 \mathrm{~kg}$ de massa gorda, sem cirurgia, durante a psicoterapia.

Nessa sessão on-line, ele estava na sala do apartamento dele, onde mora sozinho. Começou dizendo que estava emocionalmente exausto, pois há dois dias, o pai dele, demenciado pelo Alzheimer, saiu de casa escondido e assediou uma jovem vizinha dentro do elevador. Os pais da garota, furiosos, ligaram para I, cobrando uma atitude de internar o "velho safado", sob ameaça de denunciá-lo à polícia.

Contou que, imediatamente, foi no apartamento dos vizinhos do pai para se desculpar e explicar o quadro neuropsiquiátrico do pai, e tentou falar com a adolescente, mas os pais negaram e foram muito hostis com ele, voltando a ameaçar. Enquanto falava, levantou-se, foi até a cozinha, pegou um pote com castanhas e começou a comer compulsivamente. Nem parava de falar, nem de comer!

Lá estava eu, em uma cena viva de compulsão recheada por um tema que me atravessa, pois padeço de sofrimento idêntico. Quase me levanto para pegar castanhas também! Mas me levantei e disse: "I, estou me sentindo impotente como você!". É angustiante ver algo que eu só sabia, mas não presenciei.

I: "Estou me sentindo MUITO impotente, sem saída! Não sei o que fazer. Não posso internar meu pai, vou trancar ele no apartamento? Não tenho controle sobre esta situação!”.

T: "Você tem pelo menos conhecimento do que está sentindo? Coloca o pote de castanhas em cima da mesa, respira e imagina que você tem uma câmera, que entra no seu estômago e consegue reproduzir um filme com cenas dos sentimentos que lhe atravessam com esta situação do seu pai”.

I: "Vejo eu chegando na casa dele e tendo que brigar com ele, porque se comportou mal e agora será castigado por isso. Mas eu não sou pai dele e ele nunca me castigou quando eu era criança. Ele conversava e eu sabia o que fazer”.

T: "Volta na cena, experimenta chegar na casa dele e fazer o que você acha que deve ser feito".

I: "Pai, trouxe uma coisa aqui, que eu quero te mostrar. É uma filmagem no elevador do teu prédio...”.

T, no papel de pai: "Mostra aí, cara!".

I: "O senhor está entendendo o que está acontecendo?".

Peço a inversão de papéis, e I, no papel de pai: "Estou conversando com a moça, pois ela estava muito triste e perdida".

T, no papel de I: "Pai, ela não entendeu que o senhor estava conversando. E os pais dela ficaram aborrecidos por isso. E falaram comigo...”.

Neste momento, ele me interrompe e diz: "Ana, quem está perdido sou eu! Me perdi na dor de ver meu pai assim, me perdi na comida, me perdi de mim mesmo".

Pedi que ele fosse para um lugar da casa em que ele se sente mais confortável. Ele ficou em um pequeno sofá, próximo a uma varanda, com uma brecha de vista para o mar. Pedi-lhe para que posicionasse o seu corpo de forma acolhedora e fosse localizando o que ele estava precisando naquele momento, que ele pudesse se dar. Ele começou a chorar e disse: "Preciso de um tempo para digerir isso tudo e encontrar a forma mais autêntica de lidar com esta situação inevitável. Estou perdendo meu pai para o Alzheimer e não posso me perder de mim”.

Resolvi deixá-lo acompanhado dele mesmo e encerrar a sessão. Na semana seguinte, iniciamos a sessão com um compartilhamento da sessão anterior e ele falou que foi restaurador ficar naquele lugar com ele mesmo, bem como saber que pode criar esses espaços de refazimentos.

\section{ABSORVENDO E TRIANDO OS NUTRIENTES: SEÇÃO DE REFLEXÕES FINAIS}

Continuo sentindo falta dos atendimentos presenciais, em que o corpo não é subtraído como nos é on-line, mas estou convencida de que nossa capacidade imaginativa, semeada na realidade suplementar, nos afina com respeito e sensibilidade para o timing de intervenção como diretor, incluindo a função ego-auxiliar, para manter a fluidez da cena, através da nossa 
interação com os personagens, de forma mais objetiva, junto ao protagonista, ampliando o exercício comum da espontaneidade criadora, tanto no contexto psicodramático quanto no social.

Moreno (1975, p. 464) prenunciou: "Numa era tecnológica como a nossa, o destino e o futuro do princípio da espontaneidade, como padrão principal de cultura e da existência, pode depender do êxito que se obtenha para vinculá-lo aos inventos tecnológicos". Ressoa em nossa prática atual, à medida que cocriamos alternativas, através da tecnologia, porém, fundamentalmente substanciadas, o tempo todo, pela realidade suplementar, cuja infindável função imaginativa rege nossas escolhas, a partir da sensibilidade e da intuição, desabrochadas pelo arcabouço teórico estudado e pelo fino treinamento que as artes nos proporcionam.

Nos exemplos que eu descrevi, constatamos técnicas como duplo, solilóquio, inversão de papéis, espelho, dentre outras. Construímos a investigação dos percursos transferenciais. Nesses percursos, trabalhamos as lógicas afetivas de conduta, as crenças para obter afetos ou para expressar a dor de não recebê-los (Nery, 2018), que mantiveram os papéis encapsulados no imaginário dos pacientes.

Observo em minha prática que a comida, objeto de adição dos pacientes, aparece no primeiro atendimento subliminarmente, e no segundo, concretamente, mas em ambos os casos, no universo imaginário deles, desempenhando a função de representante relacional simbólico (Pinto, 2020).

O representante relacional simbólico pode ser atribuído à comida, droga, sexo ou qualquer outro objeto de adição, ou, ainda, a algo que cumpra a função imaginativa conservada. Por se tratar de algo inanimado ou, na verdade, animado pelo obeso, nesses casos, sua complementariedade é insuficiente para se constituir um contrapapel. Porém, no universo imaginativo, está presente em relação com o papel imaginário conservado, com representação simbólica do que viria a ser complementar a este papel e que será desvelado na cena psicodramática.

O representante relacional simbólico também cumpre funções simbólicas, representativas de vínculos residuais, que estão em nossa história de vida e constroem nossa subjetividade (Aguiar, 1990). Esse representante acentua a dinâmica conservada, que na vida real perpetua padrões cristalizados e o sofrimento do obeso, encarcerado em uma forma conservada de estar no mundo e no corpo, que escancara esse cárcere.

Para a prática psicodramática, importam o poder simbólico desse representante e a transfiguração dele na cena psicodramática, saindo de representante relacional simbólico para papel complementar do papel originário do vínculo residual, no qual se construiu a lógica afetiva de conduta (Nery, 2018).

A importância dessa decodificação tem razão estratégica para o diretor, por ser a visualização do complementar interno conservado (Perazzo, 1994) em cenas carregadas de força simbólica, que podem gerar insights dramáticos seguidos da catarse do protagonista e do grupo.

Para o protagonista, é uma vivência reorganizadora, cujo novo status nascendi relacional (Perazzo, 2010) dará suporte para as situações na vida cotidiana, desde aquelas habituais de alimentação, até, e principalmente, as expressas nos diversos papéis sociais ramificados no efeito cacho. É a parte educativa da psicoterapia, em que o protagonismo renovado pode ser incorporado como um modo relacional propagado para os papéis sociais, agora, em uma psicodinâmica consciente e apaziguada com a lógica afetiva de conduta predominante em sua existência, mais norteada para momentos criativos.

Compartilhamos os tempos sombrios da Covid-19, mas também as luzes que a espontaneidade e a criatividade nos permitem gerar cooperativamente, resgatando o sentido profundo de união. Como disse um dos meus pacientes: "juntos somos fortes!”.

\section{DISPONIBILIDADE DE DADOS DE PESQUISA}

Todos os dados foram gerados ou apresentados neste estudo.

\section{FINANCIAMENTO}

Não se aplica. 


\section{AGRADECIMENTOS}

Não se aplica.

\section{REFERÊNCIAS}

Aguiar, M. 1990 (1990). O Teatro terapêutico. Papirus.

Moreno, J. L. (1975). Psicodrama. Cultrix.

Nery, M. P. (2018). Vinculo e afetividade (4a ed.). Ágora.

Perazzo, S. (1994). Ainda e sempre psicodrama. Ágora.

Perazzo, S. (2010). Psicodrama: O forro e o avesso. Ágora.

Pinto, A. C. B. (2020, 7 a 10 de outubro). Obeso esteta: Encontro entre o corpo disforme e a estética da existência [Apresentação de trabalho]. Anais do 220 Congresso Brasileiro de Psicodrama. Federação Brasileira de Psicodrama. http:// icongresso.febrap.itarget.com.br/anais/index/index/cc/3 